\title{
Basin-scale effects of small hydropower on biodiversity dynamics
}

\author{
Katharina Lange ${ }^{1,2 *}$, Philipp Meier ${ }^{1}$, Clemens Trautwein ${ }^{1}$, Martin Schmid ${ }^{1}$, Christopher T Robinson ${ }^{3,4}$, \\ Christine Weber ${ }^{1}$, and Jakob Brodersen ${ }^{2,5}$
}

Construction of small hydropower plants ( $<10$ megawatts) is booming worldwide, exacerbating ongoing habitat fragmentation and degradation, and further fueling biodiversity loss. A systematic approach for selecting hydropower sites within river networks may help to minimize the detrimental effects of small hydropower on biodiversity. In addition, a better understanding of reach- and basin-scale impacts is key for designing planning tools. We synthesize the available information about (1) reach-scale and (2) basin-scale impacts of small hydropower plants on biodiversity and ecosystem function, and (3) interactions with other anthropogenic stressors. We then discuss state-of-the-art, spatially explicit planning tools and suggest how improved knowledge of the ecological and evolutionary impacts of hydropower can be incorporated into project development. Such tools can be used to balance the benefits of hydropower production with the maintenance of ecosystem services and biodiversity conservation. Adequate planning tools that consider basin-scale effects and interactions with other stressors, such as climate change, can maximize long-term conservation.

Front Ecol Environ 2018; doi: 10.1002/fee.1823

$\mathrm{F}$ reshwater biodiversity is declining at unprecedented rates, with habitat fragmentation and degradation among the key drivers (Dudgeon et al. 2006). Biodiversity, and genetic diversity in particular, may be one of our greatest assets to combat the impacts of climate change and ensure long-term ecosystem stability and provisioning of ecosystem services. The global boom in hydropower development - fueled in large part by changes in public perception following the disaster at the Fukushima Daiichi nuclear power plant in Japan in 2011 and the need to reduce atmospheric greenhouse-gas emissions - exacerbates

\section{In a nutshell:}

- Small hydropower planning often neglects large-scale ecological and evolutionary processes, as well as the cumulative effects of multiple hydropower plants

- Fragmentation by small hydropower impedes organism dispersal and migration, which can lead to reduced genetic diversity, diminishing the potential to adapt to changing environmental conditions and increasing local extinction risk

- Interactions between small hydropower and other anthropogenic stressors, such as climate change, need to be considered when assessing environmental impacts

- Spatially explicit planning tools that consider multiple objectives can substantially contribute to balancing economic needs with long-term biodiversity conservation

\footnotetext{
${ }^{1}$ Eawag (Swiss Federal Institute of Aquatic Science and Technology), Department of Surface Waters and Biogeochemistry, Kastanienbaum, Switzerland; '2Eawag, Department of Fish Ecology and Evolution, Kastanienbaum, Switzerland * (katharina.lange@eawag.ch); ${ }^{3}$ Eawag, Department of Aquatic Ecology, Dübendorf, Switzerland; ${ }^{4}$ Institute of Integrative Biology, ETH-Zürich, Zürich, Switzerland; ${ }^{5}$ University of Bern, Institute of Ecology and Evolution, Division of Aquatic Ecology Eु Evolution, Bern, Switzerland
}

this pressure on freshwater biodiversity. The trend toward greater reliance on hydropower is projected to continue until at least 2050, with small- to medium-sized hydropower plants accounting for more than $75 \%$ of the 3700 hydropower plants planned or under construction worldwide as of 2014 (Zarfl et al. 2015). Small hydropower plants (installed capacity $<10$ megawatts [MW]; Table 1 ) are often constructed in high-gradient alpine streams (Zarfl et al. 2015), ecosystems that typically support a unique fauna and flora adapted to fast-flowing, dynamic habitats.

The increase in small hydropower plants, as opposed to large hydropower schemes, is mainly a consequence of the hydropower potential of larger rivers already being exploited in most developed countries (eg in Austria; Wagner et al. 2015). Many governments are subsidizing the construction of small hydropower plants because these are perceived to have fewer adverse ecological impacts than large hydropower schemes (Kibler and Tullos 2013). Impacts of large hydropower plants on flow, sediment, and temperature regimes, affecting habitat properties and organisms, have been reasonably well studied (Ellis and Jones 2013); in contrast, local- and basinscale impacts of small hydropower plants have only rarely been examined (Jager et al. 2015). This gap is surprising given that the ecological footprint of small hydropower plants per megawatt of power produced may be disproportionally higher than that of large hydropower plants (Ziv et al. 2012; Kibler and Tullos 2013). The promotion of smaller over larger hydropower plants also means that many additional new hydropower plants will have to be built to achieve the same level of power production (Figure 1), and river basins will therefore often harbor multiple small hydropower plants. The cumulative impacts of such plants must be considered when planning 
Table 1. The three most common types of small run-of-river hydropower plants (Anderson et al. 2015; Kelly-Richards et al. 2017)

\begin{tabular}{|c|c|c|c|}
\hline \multirow[b]{2}{*}{ Characteristics } & \multicolumn{2}{|c|}{ Diversion power plants } & \multirow{2}{*}{$\frac{\text { Fluvial power plants }}{\text { Low-head in-weir schemes }}$} \\
\hline & Medium- to high-head diversion schemes & Low-head diversion schemes & \\
\hline $\begin{array}{l}\text { Electricity mainly produced } \\
\text { by }\end{array}$ & $\begin{array}{l}\text { Potential energy of the high head: } \\
\text { medium head } 30-100 \mathrm{~m} ; \\
\text { high head >100 m }\end{array}$ & $\begin{array}{l}\text { Potential energy of the head: } \\
\text { low head } 2-30 \mathrm{~m}\end{array}$ & $\begin{array}{l}\text { Potential energy of the head: } \\
\text { low head } 2-30 \mathrm{~m}\end{array}$ \\
\hline Slope gradient & High & Low & Low \\
\hline Position in river network & $\begin{array}{l}\text { Upland reaches; } \\
\text { low discharge }\end{array}$ & $\begin{array}{l}\text { Middle and lowland reaches; } \\
\text { high discharge }\end{array}$ & $\begin{array}{l}\text { Middle and lowland reaches; } \\
\text { high discharge }\end{array}$ \\
\hline Length residual flow reach & Typically $>$ I km & Typically $0.1-1 \mathrm{~km}$ & None \\
\hline Turbine type & $\begin{array}{l}\text { Fast rotation impulse turbines; } \\
\text { eg Pelton turbines }\end{array}$ & $\begin{array}{l}\text { Reaction turbines; eg Kaplan or } \\
\text { Francis turbines }\end{array}$ & $\begin{array}{l}\text { Reaction turbines; eg Kaplan } \\
\text { or Francis turbines }\end{array}$ \\
\hline
\end{tabular}

construction of new hydropower plants in order to realize the trade-off between maximizing the amount of electricity produced and minimizing the negative impacts on biodiversity. One opportunity for achieving such complex management trade-offs is through the development of powerful, spatially explicit planning tools for comparing alternative sites (Jager et al. 2015; Winemiller et al. 2016).

The objectives of this article are to (1) review the current state of knowledge about the impacts of small hydropower plants on biodiversity and ecosystem function at multiple spatial scales, (2) assess the availability of spatial planning tools, and (3) identify existing knowledge gaps. It has been suggested that the cumulative effects of multiple small hydropower plants and their interactions with other anthropogenic stressors are two major knowledge gaps for basin-scale hydropower planning (Anderson et al. 2015; Winemiller et al. 2016; Kelly-Richards et al. 2017), and so we have chosen to include reach-scale effects to assist in gaining a better understanding of the resulting basin-scale impacts of multiple hydropower plants. The impacts of small hydropower dams on evolutionary processes have rarely been examined in previous reviews, but inclusion of such processes is critical for understanding the effects of these facilities on biodiversity. We therefore begin our review with an overview of the state of knowledge of small hydropower impacts at the reach scale (Figure 2a); then turn our attention toward the basin scale, where we focus on the effects on ecological and evolutionary processes (Figure 2b); and finally, we consider interactions with other anthropogenic stressors (Figure 2c). We then discuss state-of-the-art spatial tools that are currently available for hydropower planning, and conclude with recommendations for incorporating ecological and evolutionary concepts into hydropower site selection tools for basin-scale planning.

\section{Small hydropower impacts on biodiversity and ecosystem function}

\section{Reach-scale impacts}

Diversion hydropower plants (facilities that divert water over longer [medium- to high-head schemes] or shorter [low-head schemes] distances, creating a residual flow reach between the water intake and where the water is returned) are more common than fluvial power plants (which create no residual flow reaches because electricity is produced at the weir) in Switzerland, constituting $75 \%$ of the small run-of-river hydropower plants in the country (Table 1). There is typically no substantial water storage associated with run-of-river hydropower plants, and thus they provide a continuous supply of electricity. The most obvious impacts of diversion hydropower plants are therefore usually observed in residual reaches below dams (ie river sections between water intake and the point where water is returned). Anderson et al. (2015) reviewed the effects of small- and medium-sized run-of-river hydropower plants on in-stream habitats. Reduced discharge and sediment inputs increase sediment stability and deposition of fine sediments (clogging of the stream bed), decrease organic matter retention, and alter invertebrate and fish assemblages in residual flow reaches (Kubecka et al. 1997; Benejam et al. 2014; Arroita et al. 2015). Some of these impacts may still occur downstream of the point where water is returned to the stream (eg reduced sediment transport caused by the diversion structure and altered water temperatures). There is little information available about the extent of these downstream impacts, but they are likely to be important when assessing potential cumulative effects of multiple hydropower plants.

Studies of multiple small run-of-river hydropower plants in the Czech Republic and northeastern Spain 
have shown reductions in trout biomass, body size, and body condition in residual flow reaches (Kubecka et al. 1997; Benejam et al. 2014). Although there is general consensus on the negative effects of habitat alterations on fish communities in residual flow reaches (Anderson et al. 2015), the results of research on the effects on algal and invertebrate biomass and community composition are inconclusive (Mbaka and Wanjiru Mwaniki 2015). The impacts of small hydropower plants on fundamental ecosystem processes in residual flow reaches have rarely been investigated; however, in one such study involving five small run-of-river hydropower plants it was shown that rates of organic matter breakdown and retention were lower in residual flow reaches, most

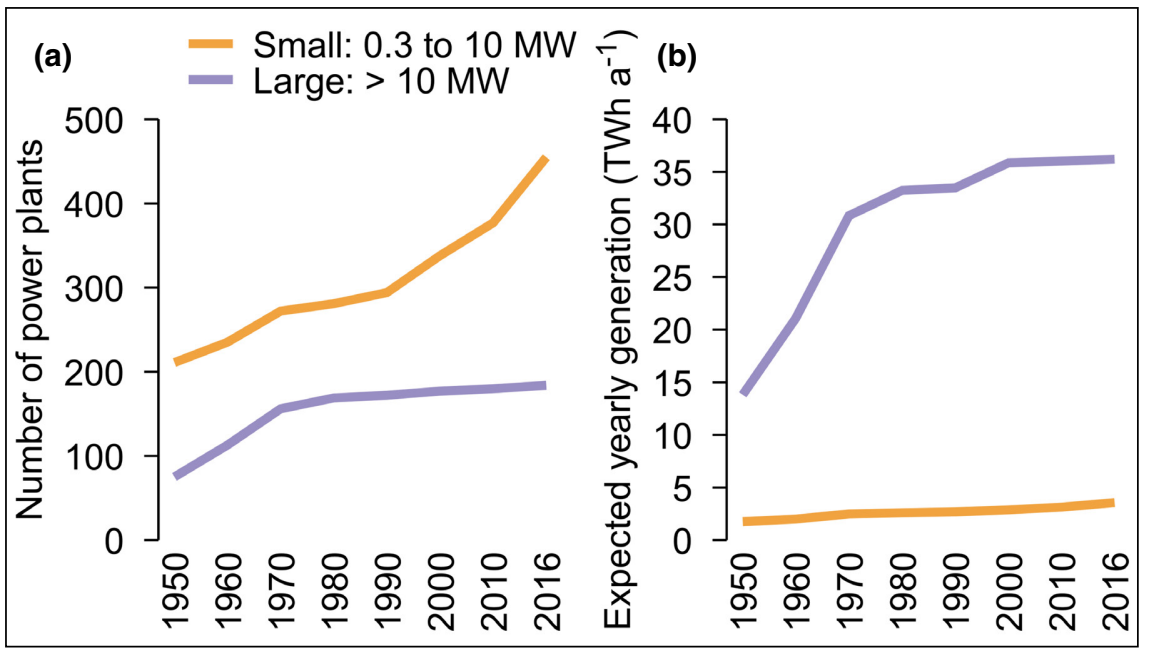

Figure 1. Comparisons between the (a) number and (b) total production of small and large hydropower plants in Switzerland (Thürler 2017). Despite contributing only marginally to overall hydropower production, the number of small hydropower plants has steadily increased over recent years in this country. TWh $a^{-1}=$ terawatt hours per year.

likely due to reduced abundance of

shredding invertebrates, which feed on coarse organic matter such as leaves (Arroita et al. 2015). Reach-scale impacts may also depend on the biogeographical and climatological contexts, as well as the operational regimes of the hydropower plants.

Residual flow reaches created by small hydropower plants in alpine regions are usually situated in river stretches with steep slopes, and as such are characterized by rapids and cascades. These high-gradient streams harbor organisms with genotypes and phenotypes well adapted to fast-flow conditions (Stelkens et al. 2012). The conversion of these environments into stable lowflow habitats, characterized by a series of pools (Benejam et al. 2014), may alleviate the selection pressure for individuals adapted to these streams, and thus locally adapted genotypes can be lost from the system. Such losses may not only reduce local genetic diversity and consequently the ability of populations to adapt to changing environmental conditions (Bellard et al. 2012) but also facilitate the invasion of non-locally adapted genotypes, an effect that has been observed in several multispecies studies in which native specialists were replaced by generalists (Marvier et al. 2004; Didham et al. 2007). An understanding of local adaptations of important species is crucial to justify the protection of unique habitats (eg high-gradient streams harboring distinct populations).

\section{Basin-scale impacts}

River network connectivity is important for the transport of particles, the movement of organisms, and the maintenance of biodiversity (Freeman et al. 2007; Altermatt et al. 2013). Barriers impede upstream movement and complicate downstream movement of organisms (Larinier 2008; Pracheil et al. 2016). Mitigation measures such as dynamic residual flows (Razurel et al. 2016), dam designs that allow sediment to pass during high-flow events, and sediment replenishment actions (Kondolf 1997) may help maintain more natural flow and sediment regimes in downstream reaches.

Dams have two distinct impacts on organism movement: they can restrict or even deter passage in the upstream direction and they can increase mortality associated with downstream passage through turbines. Fish mortality by turbines can be reduced by adding screens at water intakes or by installing fish friendly turbines, among other practices (Pracheil et al. 2016). Major efforts have been made to improve fish movement by installing fish passages, but overall these are relatively inefficient, especially for non-salmonids (Noonan et al. 2012). Upstream passage efficiency is often the only aspect examined in assessments of the success of fish passages, whereas ultimate effects - such as changes in population size, population connectivity, and life histories - are largely neglected (Godinho and Kynard 2009). Moreover, the cumulative impact of multiple hydropower plants on organism dispersal and migration may prove to be much greater than expected based on the moderate impacts of individual small plants (Kibler and Tullos 2013; Anderson et al. 2015).

In the following sections, we discuss the populationlevel consequences of dispersal limitations and impaired migration when considering basin-scale biodiversity and ecosystem functioning.

\section{Dispersal constraints}

Metapopulations consist of several distinct but often connected local populations (Gido et al. 2015). In river networks, the density and positioning of multiple 


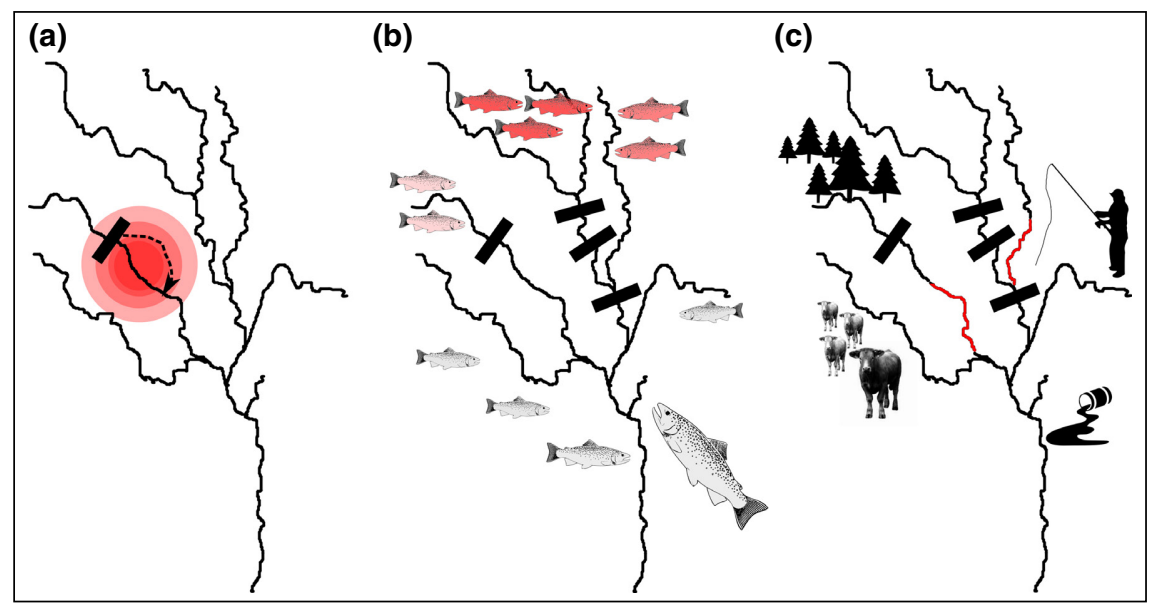

Figure 2. Impacts of small run-of-river hydropower plants are most obvious at (a) the reach scale, where residual flow reaches are experiencing discharge reductions, but multiple dams (black bars in [b]) pose constraints for organism movement, leading to isolated populations (fish in various shades of red). (c) Simultaneous exposure to other anthropogenic stressors - such as channelization (river reaches in red), cattle grazing, fishing, deforestation, and pollution - may interact with small hydropower effects.
Horreo et al. [2011]), but the rapid development of genome-wide techniques now allow for the assessment of adaptive genetic diversity and gene flow of adaptive alleles, which is crucial for defining and managing evolutionary significant units (ESUs; Holderegger et al. 2006; Frankham 2010). ESUs within a species may be a group of individuals sharing distinct phenotypical traits that have developed through local adaptations. Being able to define ESUs can justify conservation actions and the separate management of isolated populations (Frankham 2010).

Although the impacts of small hydropower plants on fish genetic diversity can be substantial, there has been limited research on multiple fish species and benthic invertebrates, which play important roles in the pro-

hydropower plants define the extent of individual, isolated river reaches, and thus the size of local populations (Ziv et al. 2012; Jager et al. 2015). Reducing local population size and increasing isolation fuels the so-called "extinction debt" (Frankham et al. 2002), and can lead to inbreeding depression (reduced biological fitness) and homozygosity, increasing the likelihood that offspring are affected by recessive or deleterious traits. Small population size also intensifies the influence of genetic drift over natural selection. The subsequent reduction in genetic diversity reduces the capacity of these populations to adapt to changing environments, which may lead to further population decline (Frankham et al. 2002; Bellard et al. 2012). The resulting extinction debt can cause local and even basin-wide species losses (Letcher et al. 2007; Horreo et al. 2011). Local extinction in turn increases the probability of basin-wide losses, because isolated river reaches no longer serve as refugia or sources for recolonization following disturbance (Letcher et al. 2007). These processes become even more important where basins are subject to multiple barriers.

The cumulative impacts of fragmentation by small hydropower plants on fish genetic diversity, gene flow, and effective population sizes have been examined in detail in only a handful of studies. In one, a study of four river basins in the Pyrenees, the genetic diversity of brown trout (Salmo trutta) populations was found to be lower in upstream reaches of fragmented basins than in a non-fragmented basin (Horreo et al. 2011), and that effective population sizes and gene flow were low in isolated upstream reaches. In the past, changes in genetic diversity and gene flow due to fragmentation have been assessed primarily by using neutral genetic markers that have no relationship to organism performance (eg the microsatellite markers used in Letcher et al. [2007] and visioning of ecosystem services. Moreover, little is known about how variables like the size of isolated river reaches, the location of dams within the river network, and interand intraspecific phenotypic distinctiveness (eg ability to pass dams, habitat requirements, effective population sizes) drive genetic diversity loss and local extinction (Letcher et al. 2007; Gido et al. 2015).

\section{Restricted migration}

Dams associated with small hydropower plants generally restrict fish migration. Any increases in mortality of out-migratory fish and any decreases in successful return migration are likely to alter the selective regime of migratory populations, often favoring resident individuals, and can lead to the loss of migratory populations (Quinn 2011). Blocked migrations can in some cases cause local populations to convert to residency (Palkovacs et al. 2008), but in other cases, evolution of residency and adaptation to a fully resident life may not evolve quickly enough, leading to local population extinction (Beamish and Northcote 1989). Furthermore, size-specific changes in migratory success associated with dams (eg due to size-selective, turbine-associated mortality; Calles et al. 2010) may alter population life-history strategies, which can subsequently affect ecosystem functioning (eg through trophic cascades; Post et al. 2008). Due to a paucity of published research on the effects of multiple small-scale hydropower plants on fish life histories, we summarized the observed effects of multiple larger dams and assumed the effects of small dams to be similar.

Small hydropower plants are typically located at relatively large distances from the ocean, so that populations of anadromous fish inhabiting reaches above small hydropower dams must undertake long migrations both as 
juveniles and as returning adults. Such long-distance migrants are especially likely to experience the detrimental effects of increased migration costs, since they already have high costs associated with migration in terms of energy expenditure and mortality rates. In addition, migratory populations from upper tributaries often exhibit different patterns of migration than migratory populations in mainstem rivers (eg return migration occurs earlier in the season; Quinn 2011). The loss of upper tributary migratory populations will therefore constitute an uneven loss within the migratory phenotype space (ie a specific loss of long distance and early migrating individuals, potentially adapted to reproduction in small cold streams).

Migratory fish populations within river networks usually consist of connected local populations within a metapopulation network rather than a single large population. For fish populations migrating within river networks, it has been shown that adult salmonids in mainstems are often dependent on spawning migrations to the upper tributaries (Northcote 1997) and therefore resemble members of multiple distinct populations (Figure 3). Importantly, these distinct populations often display unique migratory patterns in terms of migration-residency, timing of migration, and migratory distance, and consequently contribute to long-term ecosystem stability (Schindler et al. 2015). Differences in migratory patterns within and among river basins make it difficult to identify a one-pattern-fits-all model to predict the effects of small hydropower plants.

Extensive information is available on the migratory patterns of some commercially important fish populations that undertake long-distance migrations (eg salmon migrating from nursery streams to the ocean; Quinn 2011), but detailed information about the migratory patterns of many fish populations, or whether they are even migratory at all, is currently lacking especially for fish migrating within river systems. As a result, the loss of lifehistory diversity due to fragmentation by small hydropower can lead to reduced levels of adult density and population stability (Schroeder et al. 2015).

\section{Interactions with other anthropogenic stressors}

Small hydropower plants are often not the only anthropogenic stressor affecting a river basin, and their adverse effects may therefore interact with other stressors. These interactions may create "ecological surprises", in which the combined response is either larger (ie synergistic effects) or smaller (ie antagonistic effects) than expected based on the sum of the individual effects (Folt et al. 1999). A meta-analysis of 75 articles assessing the effects of multiple stressors - including excess nutrients as well as hydrological and morphological alterations - on river fish and macroinvertebrates suggested that both synergistic and antagonistic effects were common (Nõges et al. 2016).

Understanding the interactions between small hydropower plants and other stressors is therefore crucial for

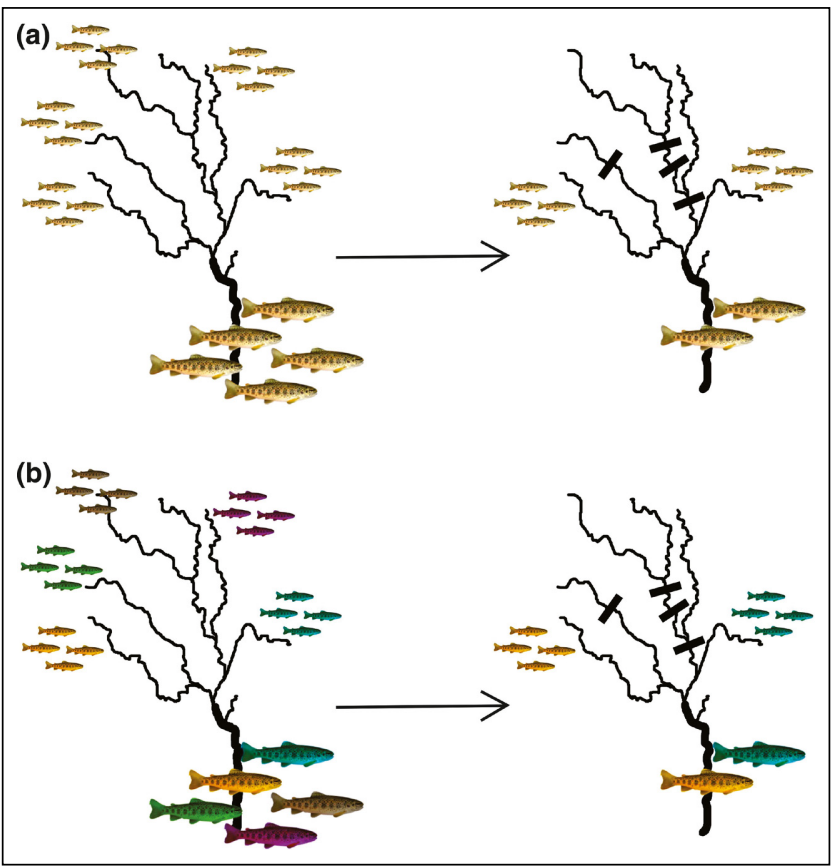

Figure 3. Predicting the impact of barriers (black bars) restricting access to tributary spawning habitats (thin lines) for mainstem (thick lines) migratory river fish. (a) When considering mainstem river fish as a single population (same colored fish), partially restricted access to multiple tributaries would not necessarily predict a loss of biodiversity; (b) however, mainstem river fish may resemble migratory metapopulations, with genetically distinct populations in different tributaries (various colored fish). Blocking migration will reduce both genetic diversity and mainstem migratory adult population stability.

hydropower site selection, but to date, there have been no systematic studies of streams impacted by these facilities and additional stressors (Anderson et al. 2015). The lack of knowledge on how hydropower development will interact with climate change, for instance, is a source of great uncertainty when attempting to project future ecological and evolutionary impacts (Hering et al. 2014; Navarro-Ortega et al. 2014). Changes in discharge patterns are not only important for the long-term economic viability of a hydropower plant, but discharge and temperature regime shifts can also affect organism life histories and ecosystem functions (Martínez et al. 2016). Climate change may further reduce connectivity within river networks by increasing the frequency of more severe disturbance events (eg stream drying) and by altering the dispersal limits of temperature-dependent species (Hering et al. 2014; Navarro-Ortega et al. 2014).

\section{Analytical tools for positioning of small hydropower plants}

As noted above, diversion hydropower plants can have effects on riverine ecosystems well beyond the residual flow reach. In contrast to local impact assessments, 


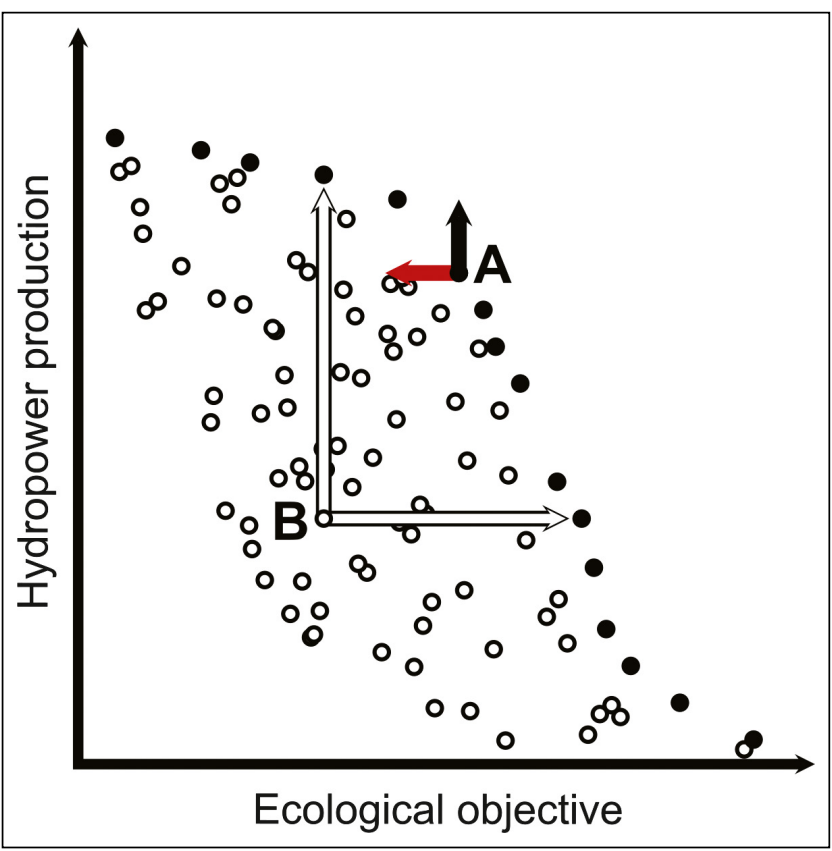

Figure 4. Within a set of Pareto-optimal hydropower system configurations (solid circles), one objective can be attained only at the expense of other objectives; for example, if power production of a given configuration ("A") is to be increased (black arrow), this is only possible by diminishing the ecological objective (red arrow). For non-optimal configurations ("B", open circles), hydropower production and the ecological objective can be improved simultaneously (white arrows). Such nonoptimal solutions are always outperformed by at least one solution in the Pareto-optimal set.

the cumulative effects of multiple barriers require planning at the basin scale (Winemiller et al. 2016). In river basins with multiple existing or planned hydropower schemes, assessment of long-term ecosystem stability and evolutionary impacts is complex. The position of each hydropower plant within the river basin should therefore be compared with alternative sites based on multiple objectives, such as increasing economic gains and minimizing negative ecological impacts (Kuby et al. 2005; Jager et al. 2015).

Multi-objective optimization is often applied to waterresource issues (Labadie 2004). Optimal solutions form the so-called Pareto-optimal set, in which the improvement of one objective can be achieved only at the expense of one or multiple other objectives (Figure 4). While investment cost, expected revenue, and other economic objectives can be calculated based on power plant design and hydrological parameters, the evaluation of ecological impacts at the basin scale is far more difficult because such assessment depends on the environmental setting and the organisms present in the system.

A number of ecological assessment methods with regard to positioning hydropower plants within river networks have been proposed. For example, Marxan - a spatially explicit planning software developed for ecosystem management - has been extended to account for river connectivity (Hermoso et al. 2015). In this program, a river network is divided into different zones, consisting of a river reach and its contributing area, and a conservation priority and cost for protection is defined for each zone. The algorithm then identifies a least-cost spatial arrangement of protected and unprotected zones, while maintaining a preference for high river network connectivity and respecting conservation features (eg unique habitats). Such spatially explicit planning is indispensable for planning a hydropower system.

In large river systems where migratory fish species represent a substantial share of fish biodiversity and biomass production, explicit migration models provide a major expansion of habitat-based indices. Such a model was proposed by Ziv et al. (2012) to assess trade-offs between power production and fish biodiversity and biomass in the Mekong River basin. To calculate fish biodiversity, the authors first assigned a typical migratory distance to each species based on basin-wide presence-absence data, and for each sub-basin they calculated a local carrying capacity proportional to discharge and basin size. They then estimated the proportion of offspring returning to the floodplain, based on migration distance, carrying capacity, and abundance of non-migratory species within each sub-basin. For each species, this proportion was reduced by dams limiting accessibility to tributary basins, leading to a decline in fish diversity and biomass. On the basis of Pareto-optimal solutions, Ziv et al. (2012) were able to identify dam configurations that were least harmful for fish while simultaneously providing high levels of power production.

\section{Conclusions}

The economic benefits derived from investing in small hydropower projects can be weighed against their adverse ecological impacts for any particular river basin. Spatially explicit planning tools are well suited for selecting hydropower sites that would generate the highest economic return and have the smallest impact on biodiversity (Jager et al. 2015), and may therefore provide a means of determining the minimum size of hydropower plants that should be promoted in a given river basin. To quantify this trade-off, we argue that multiple drivers of biodiversity need to be adopted as indicators.

Protection of unique habitats harboring locally adapted populations of important species is an essential component of maintaining freshwater biodiversity, and knowledge of the presence of locally adapted populations is crucial for the prioritization of habitats. A potential indicator for such populations is the presence of ESUs (Frankham 2010). If there is no information about the genetic makeup of important taxa, then the proportion of unique habitats within a river basin is one indicator that should be taken into account in hydropower planning. Habitat requirements, which differ among species and life 
stages, must be taken into account by including indicators for habitat size and diversity needed to sustain local populations. If some species inhabiting a basin require access to several spatially separated habitats to complete their life cycles, then connectivity among these habitats must be maintained. In addition, specific river sections may be disproportionally important for a large number of species; for instance, some tributaries may provide particularly crucial spawning and nursing habitats. Highresolution environmental and species-specific data must be collected to quantify the available stream habitat and describe populations present in the river basin. Potential synergistic and antagonistic interactions between small hydropower plants and other stressors, such as climate change, can alter the prevailing habitat conditions and therefore modify indicators. Such interactions must therefore be assessed and included in planning.

When selecting sites for new small hydropower plants, indicators such as those described above can be used as objectives to balance hydropower production and its impacts on stream ecosystems. Designing spatially explicit planning tools that account for multiple such objectives will be invaluable for policy makers and resource managers. The set of explicit solutions obtained by applying optimization tools can then assist stakeholders and decision makers in developing a shared view of the problem and negotiating policies for managing environmental resources (Hurford et al. 2014).

\section{Acknowledgements}

We thank the Department of Fish Ecology and Evolution group for discussions. This research was funded by the Swiss Competence Center for Energy Research - Supply of Electricity (SCCER-SoE) under contract CTI/ 2013/0288.

\section{References}

Altermatt F, Seymour M, and Martinez N. 2013. River network properties shape $\alpha$-diversity and community similarity patterns of aquatic insect communities across major drainage basins. $J$ Biogeogr 40: 2249-60.

Anderson D, Moggridge H, Warren P, et al. 2015. The impacts of "run-of-river" hydropower on the physical and ecological condition of rivers. Water Environ J 29: 268-76.

Arroita M, Aristi I, Díez J, et al. 2015. Impact of water abstraction on storage and breakdown of coarse organic matter in mountain streams. Sci Total Environ 503/504: 233-40.

Beamish RJ and Northcote TG. 1989. Extinction of a population of anadromous parasitic lamprey, Lampetra tridentata, upstream of an impassable dam. Can J Fish Aquat Sci 46: 420-25.

Bellard C, Bertelsmeier C, Leadley P, et al. 2012. Impacts of climate change on the future of biodiversity. Ecol Lett 15: 365-77.

Benejam L, Saura-Mas S, Bardina M, et al. 2014. Ecological impacts of small hydropower plants on headwater stream fish: from individual to community effects. Ecol Freshw Fish 25: 295-306.

Calles O, Olsson IC, Comoglio C, et al. 2010. Size-dependent mortality of migratory silver eels at a hydropower plant, and implications for escapement to the sea. Freshwater Biol 55: 2167-80.
Didham RK, Tylianakis JM, Gemmell NJ, et al. 2007. Interactive effects of habitat modification and species invasion on native species decline. Trends Ecol Evol 22: 489-96.

Dudgeon D, Arthington AH, Gessner MO, et al. 2006. Freshwater biodiversity: importance, threats, status and conservation challenges. Biol Rev 81: 163-82.

Ellis LE and Jones NE. 2013. Longitudinal trends in regulated rivers: a review and synthesis within the context of the serial discontinuity concept. Environ Rev 21: 136-48.

Folt CL, Chen CY, Moore MV, et al. 1999. Synergism and antagonism among multiple stressors. Limnol Oceanogr 44: 864-77.

Frankham R. 2010. Challenges and opportunities of genetic approaches to biological conservation. Biol Conserv 143: 1919-27.

Frankham R, Briscoe DA, and Ballou JD. 2002. Introduction to conservation genetics. Cambridge, UK: Cambridge University Press.

Freeman MC, Pringle CM, and Jackson CR. 2007. Hydrologic connectivity and the contribution of stream headwaters to ecological integrity at regional scales. J Am Water Resour As 43: 5-14.

Gido KB, Whitney JE, Perkin JS, et al. 2015. Fragmentation, connectivity and fish species persistence in freshwater ecosystems. In: Closs GP, Krkosek M, and Olden JD (Eds). Conservation of freshwater fishes. Cambridge, UK: Cambridge University Press.

Godinho AL and Kynard B. 2009. Migratory fishes of Brazil: life history and fish passage needs. River Res Appl 25: 702-12.

Hering D, Carvalho L, Argillier C, et al. 2014. Managing aquatic ecosystems and water resources under multiple stress - an introduction to the MARS project. Sci Total Environ 503/504: 10-21.

Hermoso V, Filipe AF, Segurado P, et al. 2015. Filling gaps in a large reserve network to address freshwater conservation needs. J Environ Manage 161: 358-65.

Holderegger R, Kamm U, and Gugerli F. 2006. Adaptive vs neutral genetic diversity: implications for landscape genetics. Landscape Ecol 21: 797-807.

Horreo JL, Martinez JL, Ayllon F, et al. 2011. Impact of habitat fragmentation on the genetics of populations in dendritic landscapes. Freshwater Biol 56: 2567-79.

Hurford AP, Huskova I, and Harou JJ. 2014. Using many-objective trade-off analysis to help dams promote economic development, protect the poor and enhance ecological health. Environ Sci Policy 38: 72-86.

Jager HI, Efroymson RA, Opperman JJ, et al. 2015. Spatial design principles for sustainable hydropower development in river basins. Renew Sust Energ Rev 45: 808-16.

Kelly-Richards S, Silber-Coats N, Crootof A, et al. 2017. Governing the transition to renewable energy: a review of impacts and policy issues in the small hydropower boom. Energ Policy 101: 251-64.

Kibler KM and Tullos DD. 2013. Cumulative biophysical impact of small and large hydropower development in Nu River, China. Water Resour Res 49: 3104-18.

Kondolf GM. 1997. Hungry water: effects of dams and gravel mining on river channels. J Environ Manage 21: 533-51.

Kubecka J, Matena J, and Hartvich P. 1997. Adverse ecological effects of small hydropower stations in the Czech Republic: 1. Bypass plants. Regul River 13: 101-13.

Kuby MJ, Fagan WF, ReVelle CS, et al. 2005. A multiobjective optimization model for dam removal: an example trading off salmon passage with hydropower and water storage in the Willamette basin. Adv Water Resour 28: 845-55.

Labadie JW. 2004. Optimal operation of multireservoir systems: state-of-the-art review. J Water Res Pl 130: 93-111.

Larinier M. 2008. Fish passage experience at small-scale hydroelectric power plants in France. Hydrobiologia 609: 97-108.

Letcher BH, Nislow KH, Coombs JA, et al. 2007. Population response to habitat fragmentation in a stream-dwelling brook trout population. PLoS ONE 2: e1139. 
Martínez A, Larrañaga A, Pérez J, et al. 2016. Climate modulates the magnitude of the effects of flow regulation on leaf-litter decomposition. Aquat Sci 79: 507-14.

Marvier M, Kareiva P, and Neubert MG. 2004. Habitat destruction, fragmentation, and disturbance promote invasion by habitat generalists in a multispecies metapopulation. Risk Anal 24: 869-78.

Mbaka JG and Wanjiru Mwaniki M. 2015. A global review of the downstream effects of small impoundments on stream habitat conditions and macroinvertebrates. Environ Rev 23: 257-62.

Navarro-Ortega A, Acuña V, Bellin A, et al. 2014. Managing the effects of multiple stressors on aquatic ecosystems under water scarcity. The GLOBAQUA project. Sci Total Environ 503/504: $3-9$.

Nõges P, Argillier C, Borja Á, et al. 2016. Quantified biotic and abiotic responses to multiple stress in freshwater, marine and ground waters. Sci Total Environ 540: 43-52.

Noonan MJ, Grant JWA, and Jackson CD. 2012. A quantitative assessment of fish passage efficiency. Fish Fish 13: 450-64.

Northcote TG. 1997. Potamodromy in Salmonidae - living and moving in the fast lane. N Am J Fish Manage 17: 1029-45.

Palkovacs EP, Dion KB, Post DM, et al. 2008. Independent evolutionary origins of landlocked alewife populations and rapid parallel evolution of phenotypic traits. Mol Ecol 17: 582-97.

Post DM, Palkovacs EP, Schielke EG, et al. 2008. Intraspecific variation in a predator affects community structure and cascading trophic interactions. Ecology 89: 2019-32.

Pracheil BM, DeRolph CR, Schramm MP, et al. 2016. A fish-eye view of riverine hydropower systems: the current understand- ing of the biological response to turbine passage. Rev Fish Biol Fisher 26: 153-67.

Quinn TP. 2011. The behavior and ecology of Pacific salmon and trout. Seattle, WA: University of Washington Press.

Razurel P, Gorla L, Crouzy B, et al. 2016. Non-proportional repartition rules optimize environmental flows and energy production. Water Resour Manag 30: 207-23.

Schindler DE, Armstrong JB, and Reed TE. 2015. The portfolio concept in ecology and evolution. Front Ecol Environ 13: 257-63.

Schroeder RK, Whitman LD, Cannon B, et al. 2015. Juvenile lifehistory diversity and population stability of spring Chinook salmon in the Willamette River basin, Oregon. Can J Fish Aquat Sci 73: 921-34.

Stelkens RB, Jaffuel G, Escher M, et al. 2012. Genetic and phenotypic population divergence on a microgeographic scale in brown trout. Mol Ecol 21: 2896-915.

Thürler G. 2017. Statistik der Wasserkraftanlagen der Schweiz. Bern, Switzerland: Swiss Federal Office of Energy.

Wagner B, Hauer C, Schoder A, et al. 2015. A review of hydropower in Austria: past, present and future development. Renew Sust Energ Rev 50: 304-14.

Winemiller KO, McIntyre PB, Castello L, et al. 2016. Balancing hydropower and biodiversity in the Amazon, Congo, and Mekong. Science 351: 128-29.

Zarfl C, Lumsdon A, Berlekamp J, et al. 2015. A global boom in hydropower dam construction. Aquat Sci 77: 161-70.

Ziv G, Baran E, Nam S, et al. 2012. Trading-off fish biodiversity, food security, and hydropower in the Mekong River Basin. P Natl Acad Sci USA 109: 5609-14. 